\title{
Getting a bigger picture: Teaching film in transcultural societies
}

\author{
Petra Anders* - Humboldt-Universität zu Berlin, Germany
}

\begin{abstract}
This article presents the main results of an empirical study on the use of feature films in primary and secondary schools, which was carried out as part of the European Union project Film: A Language Without Borders in 2018. The aim of the project, by Vision Kino (Germany), the British Film Institute and the Danish Film Institute, was to familiarize children and young adults with European film culture and to promote transcultural learning. The author contextualized the results of 28 individual interviews with teachers using the concepts of literary learning (Spinner, 2006) and transculturality (Welsch, 1999), arguing that films can act as a springboard to support more critical conversations in class and to build cultural repertoires. Mobilizing social and cultural practices surrounding a film screening can help to foster a collective sense of well-being and an arena for dissent. Teaching film can create a valuable sense of community in modern diverse classrooms.
\end{abstract}

Keywords: transcultural learning; literary learning; film education; empirical study; European film culture

Film offers opportunities for viewers to encounter other forms of life, and might thus be seen to create a reservoir of common experience. In theory, film is an inclusive medium that can address and attract all people, regardless of their ability to read, native language, ethical persuasion, age and gender, and cognitive, bodily and emotional constitution (Anders, 2016; Riegert and Anders, 2018).

For Wolfgang Welsch (1999: 200), our contemporary society is marked by a sense of transculturality:

... a multi-meshed and inclusive, not separatist and exclusive understanding of culture. It intends a culture and society whose pragmatic feats exist not in delimitation, but in the ability to link and undergo transition. In meeting with other lifeforms there are always not only divergences but opportunities to link up, and these can be developed and extended so that a common lifeform is fashioned which includes even reserves which hadn't earlier seemed capable of being linked in. Extensions of this type represent a pressing task today.

Film might offer the next generation of a so-called transcultural society a reservoir of role models, provide answers to unanswered questions, offer alternative patterns of action, and serve as 'overtures for real life' (Barthelmes, 2006: 5). For children especially, films are close to the real world. Children frequently pick films mainly thematically, in relation to their own situation (Tatsch, 2010: 143) and adopt the perspectives of different film characters (ibid.: 145-8). 
By teaching film, some of the aspects of literary learning discussed by Spinner (see Spinner, 2006, translated in this issue of the Film Education Journal) may foster the 'ability to link and undergo transition' (Welsch, 1999: 200). To learn with and about film is to understand the perspectives of characters, to become familiar with the discussions surrounding a given film or body of films, and to engage with the inconclusive nature of the process of constructing meaning - three aspects that would also seem to be important in shaping a transcultural society. Literary learning becomes transcultural learning when one considers some of the far-reaching goals of facilitating encounters with film: children learn with the help of audiovisual texts to identify their own needs and desires, and to better understand themselves (identity formation); they come to recognize inner conflicts and relationships between characters that lead to psychological understandings of what happens in the world; films enhance moral judgement (thinking about law and justice, guilt and forgiveness), develop fantasy and imagination, and broaden world knowledge and the ability to enhance one's aesthetic perception (Spinner, 2017: 144-5). Broadly speaking, therefore, fostering film literacy entails not only making (new) audiences familiar with how film functions as a medium, but also encouraging participation in cultural life and personality development through knowledge of previous contents and experiences of one's own culture and that of others (Kepser and Abraham, 2016: 108).

\section{Transcultural learning in the film education project Film: A Language Without Borders}

To date, there exist only a few international research projects exploring film education, and even less empirical research investigating the effects of such film education work (see Anders, 2018). In looking to emphasize the possibilities of transcultural learning, this article refers to the project Film: A Language Without Borders, a programme funded by Creative Europe in 2018:

The Danish Film Institute, Vision Kino in Germany, and BFI [British Film Institute], developed resources for seven feature films, and three short films, that each explored the experience of children arriving in an unfamiliar place, or otherwise having an experience of being different. Throughout 2018, cinemas in the three countries showed the films, contextualized by talks and discussion. (BFI, 2019: n.p.)

The project featured contemporary films such as Paddington (2014), Ernest \& Célestine (2012), Billy Elliot (2000), Sing Street (2016) and My Life as a Courgette (2016), as well as black-and-white films such as Emil and the Detectives (1931) and Jemima and Johnny (1966) (BFI, 2019), accompanied by specific teaching materials (Vision Kino, 2018) designed for each of the films, which teachers could use to prepare and follow up the viewing of the films.

The research accompanying the project focused on exploring the question of whether film really was a language without borders for the students and teachers in the project. In this context, the metaphorical notion of a 'language without borders' means: Was the content of the film accessible for all students whatever their mother tongue, place of origin and cognitive abilities, and could learning with film support the ability to link and undergo processes of transition in transcultural societies?

Inner processes such as transcultural learning are, of course, difficult to quantify, and can prove challenging to examine. Albrecht and Hornberger (2014) have thus suggested investigating the contexts that may foster capabilities in children and 
young adults, rather than attempting to investigate the formation and experiences themselves. Short teaching experiences cannot guarantee identity formation, literary and intercultural learning, but often make these things possible. Teaching conditions, such as the materials accompanying a film screening, the preparation of the screening, the screening itself and the debriefing activities, could be examined. However, any results are relative, according to the assumption that interviews, student texts and drawings are only excerpts of what is imagined and experienced by the child or young adult themselves in a much more differentiated, contingent manner (Spinner, 1998: 51). Nevertheless, the following research serves as an exploratory study that may provide insights into the effect of using film in this manner within an educational context.

In Germany, the project was part of School Cinema Weeks, an ongoing programme in which schoolchildren watch and discuss films together with facilitators in local cinemas. In Baden-Württemberg, children from 13 primary school classes, aged 7 to 10 years, attended film screenings of Paddington, Ernest \& Célestine and My Life as a Courgette. In Bremen, pupils aged 10 to 13 years from 6 secondary schools (4 comprehensive schools and 2 grammar schools) watched the British film Billy Elliot. In most classes, students of several different nationalities of origin were represented, and class compositions in terms of attainment level varied from a homogeneously high-performing class to a very heterogeneous, low-performing class, as well as an inclusion class with an increased need for support. Classes included students with cultural backgrounds from Turkey, India, Greece, Russia, Germany, Kosovo, Albania, Belarus, Senegal, Ghana, Romania, Syria, Italy, Palestine, Spain and Lebanon. Among the secondary school students, there were 12 students with special needs status. The experience of the teachers ranged from 2 to 35 years in their profession, and the majority of the teachers had already attended School Cinema Weeks at least once. The researchers Ines Freitag-Amtmann, Johanna Rehak and Sarah-Miriam Tiedeke consulted 19 teachers with guideline-based telephone interviews with a duration of about thirty minutes.

In the UK, the Middlesbrough Institute of Modern Art arranged screenings of Paddington, My Life as a Courgette, The Red Balloon (1956), Emil and the Detectives (1964), Ernest \& Célestine and Palle Alone in the World (1949) to attract local families to watch free, family-friendly films (most of which were drawn from international cinema) in a relaxed environment including post-screening activities such as drawing, craftwork and discussion sessions exploring themes and ideas from the films (see Figure 1). The film education scholar Michelle Cannon visited a screening of Paddington at the Gulbenkian Cinema (University of Kent) attended by a group of 131 children from two local primary schools, with an age range of 7 to 10 years. Although there is a high density of migrants living in Kent, the children who came to the screening were largely, though not exclusively, British-born children from a middle-class background. A facilitator from the British Film Institute (BFI) conducted a question and answer session after the film, exploring the meaning of 'home' (see Figure 2). The BFI Southbank also screened Jemima and Johnny and Palle Alone in the World to an audience consisting of children from four schools. Of the teachers who responded positively to post-screening emails, one brought a group of 30 children aged 8 and 9 years (Years 3 and 4) and another brought 55 children aged 9 and 10 years (Years 4 and 5). The screening was run by a BFI facilitator using the same format as the question and answer session at the Gulbenkian in Kent. As a central London location, the BFI Southbank attracted schools with diverse intakes of children, and many different ethnicities were represented in the audience. The main research target group here was 85 children aged 6 to 10 years, and telephone interviews were conducted with four teachers and one learning coordinator. 


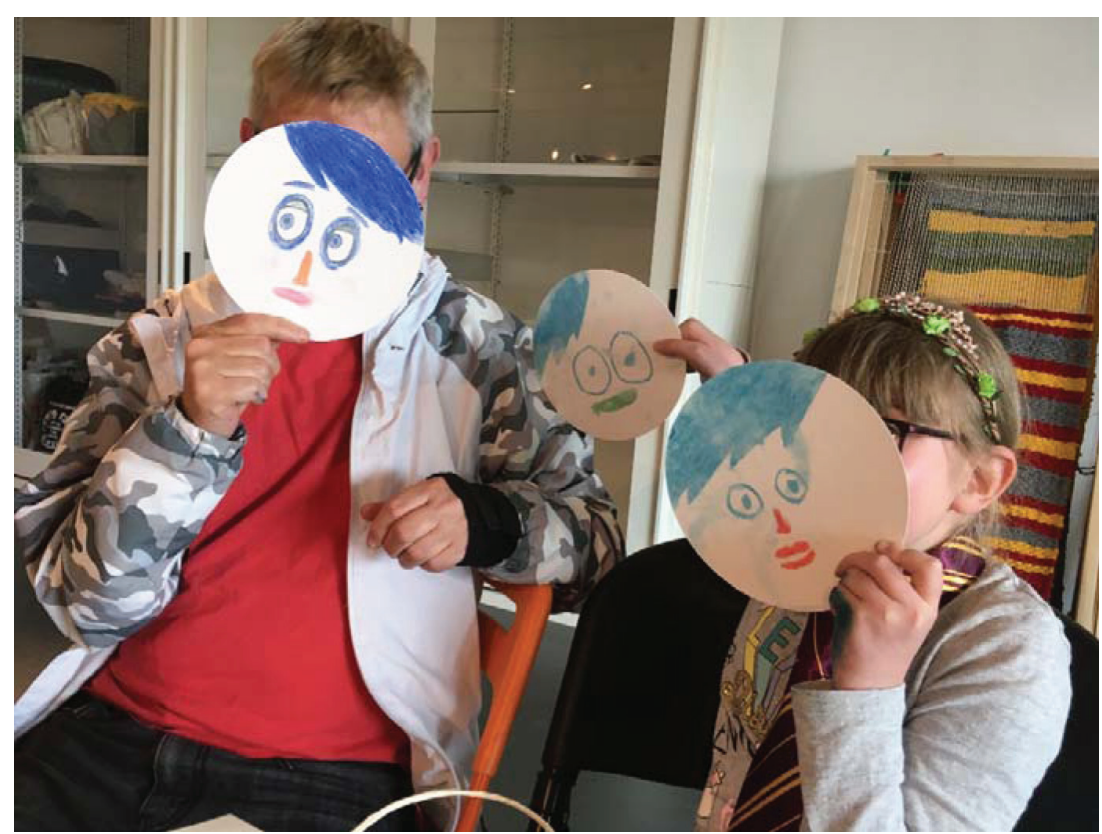

Figure 1: Post-screening activities for My Life as a Courgette at the Middlesbrough Institute of Modern Art

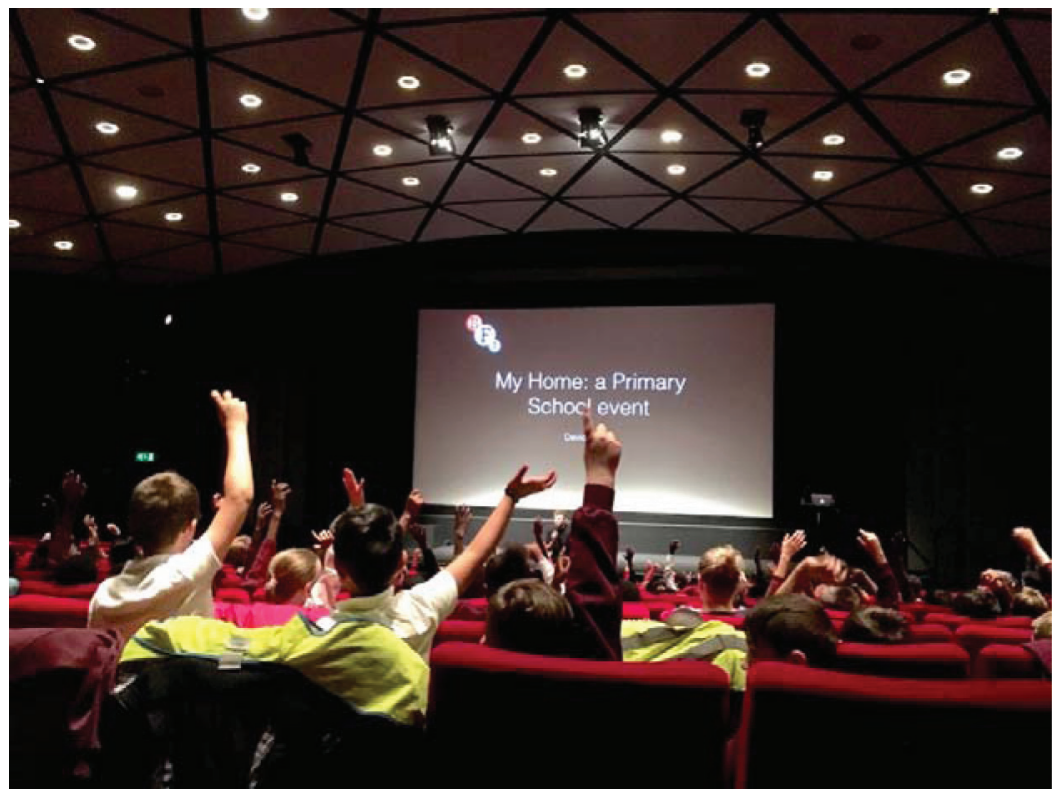

Figure 2: Screening films on the topic of 'home'

In Denmark, the research included screenings for specially invited schools at the Danish Film Institute (DFI) in Copenhagen, and screenings in the very popular School Cinema, alongside streaming of films on Filmcentralen.dk. The films screened were Billy Elliot, the Danish film Drømmen (2006), Ernest \& Célestine, Fighter (2007), My Life as a Courgette, Paddington, and the short films The Red Balloon, Jemima and Johnny and Palle Alone in the World. The researcher Pernille Clemmensen observed participants during three film screenings (Fighter, Billy Elliot and Paddington), and arranged three group interviews with a total of 15 students (aged 8 to 14 years) with a focus on sharing their immediate experiences following the screenings, and on studying how 
the students handled discussions around potentially emotional topics arising from the films. The researcher also visited two schools in Copenhagen to observe the teaching of the educational materials accompanying Palle Alone in the World and Paddington, and interviewed four primary school teachers about their experiences with the films Fighter, Billy Elliot and Paddington.

\section{Outcomes of the research}

The study as a whole was based on 28 individual interviews with teachers, 3 group interviews with a total of 45 students, 2 observed school visits and 6 observed film screenings. This article focuses only on the results of the interviews with the teachers.

In the questionnaire sent to project participants, researchers asked: (1) about experiences of the film project in general and teachers' impressions of film as a language without borders within the teaching context; (2) if the films had promoted transcultural learning in terms of recognition of one's own culture and those of others, change of perspective, acceptance and tolerance of the other, reflection about values and standards; and (3) about obstacles and challenges when working with the selected films.

The transcripts of the interviews were categorized and analysed, and the researchers extracted key statements from the interviews. Reflecting on that process of analysis, this article gives an insight into some of the main potentials and obstacles that the teachers highlighted from their experiences of teaching with the selected films.

\section{Was the content of the film accessible for all students?}

None of the teachers mentioned language obstacles for children and young adults while working with the films, although the films were offered only in the language of the classroom (German, English, Danish). In general, the teachers seemed to regard film as an inclusive medium providing low-level access. They recounted how the children responded to the audiovisual material in visceral ways to express feelings, and how children's knowledge of the films was linked to visual, acoustic and emotional experiences. Teachers described how the films induced emotions that were more concrete, and thus more memorable and personally relevant. It was felt that the colours and music of a film articulate a significant amount of emotion, and thus offered a bridge to verbal expression. In general, teachers found that suspense and fun were two important components in students being able to gain access to a film. Given the visual language of the films, students with a limited vocabulary were still able to gain significant experiences and insights. Furthermore, it was found that bilingual aspects made films accessible: European films served as a source of empowerment for minority groups, in that they served to strengthen bilingual students' feelings of being a greater part of the community when their mother tongue was represented within an unfamiliar framework. As one teacher remarked about the film Fighter (a film in Danish and Turkish with English subtitles): 'Many of my Turkish students expressed delight at the amount of Turkish spoken. It really made an impression on them that it wasn't just one sentence in Turkish but whole episodes. I certainly felt that the bilingual students felt "seen".' In general, teachers felt that the study guides were very useful, as they opened up new haptic and linguistic possibilities for the students, and offered tasks using a mixture of action and reflection. In particular, the accompanying materials for primary schools provided suggestions for both drawing and writing tasks, meaning that everyone was able to participate, even pupils who were not yet reading and writing fluently. 


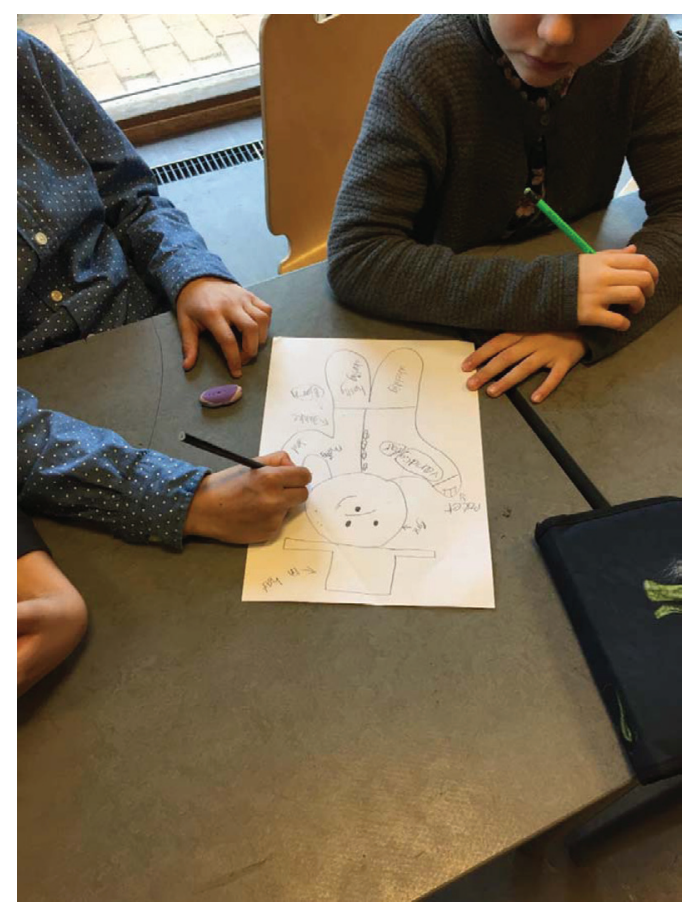

Figure 3: Post-screening activities to characterize Paddington

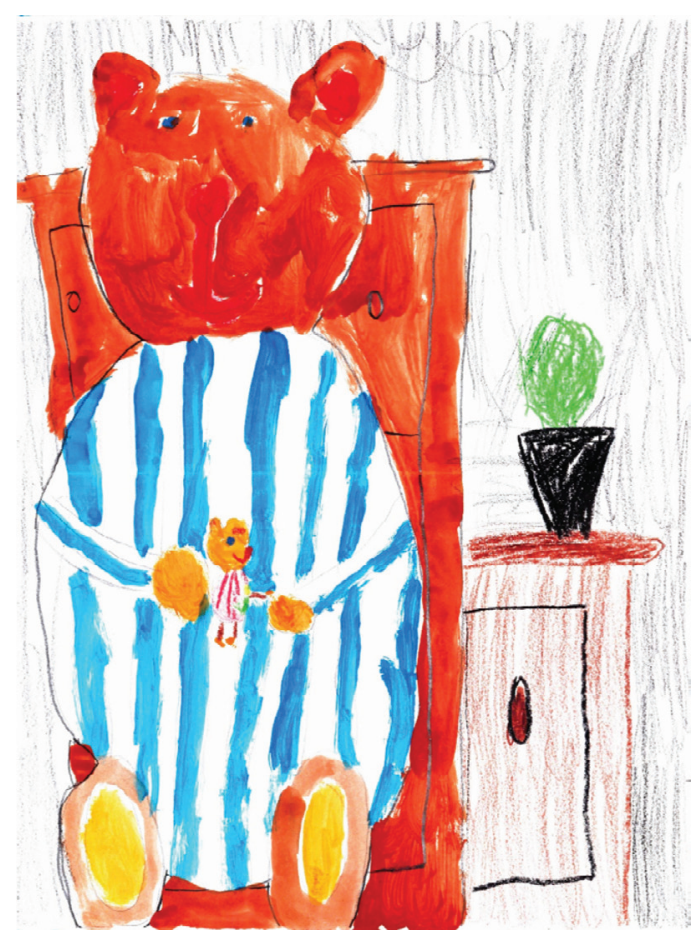

Figure 4: A primary school child expresses the friendship of Ernest and Célestine

Teachers found that using visual language and aspects of role play helped children express their own feelings. For example, one primary teacher asked their first-grade students to each play Paddington in a situation where the character was sitting alone at the railway station. The students felt what it is like to depend on others who are passing by, and talked about these feelings in class. 
Teachers found that making collages in secondary school classes made working with a film accessible for all, and that classrooms tended to become more inclusive through working with film. Even students with poor language skills or intellectual disabilities were able to comment on the film afterwards, even though their understanding remained mostly at a superficial level. In general, the teachers felt that the drawings and collages produced after the screenings illustrated that basic understanding was present in the vast majority of students, at least in rudimentary form (see Figure 3 and Figure 4 for examples of these drawings).

Although language did not seem to depict a problem in the classes represented in this study, it should not be underestimated that talking about film can produce a significant linguistic and cognitive challenge, and that action- and productionoriented comprehension tasks should be combined with more traditional modes of communication skills in order to fully exploit the potential of exploring film in the classroom.

\section{Could learning with film support the ability to link and undergo transition in transcultural societies?}

Teachers found that films featured in the project were useful as a means for talking implicitly about politics. One teacher said: 'I think it was good to pick up on a good thing, especially without having to go directly into the subject of refugees right now.' Furthermore, teachers found that the films provided a means through which to reflect upon social values, in that they opened up opportunities for making complex meanings accessible through collective viewing and talking, even for the teachers themselves. One teacher said: 'I have thought many times about the film, refugees, and losing my home since the experience; watching the film with the discussions we' $d$ had prior and following really deepened the impact.' Teachers also found that films led to an understanding of local communities or, in the case of older films such as Jemima and Johnny (1966), they helped students understand the extent to which society had changed. In general, films helped foster empathy, for example when students were deeply touched by a film character or experienced new perspectives. One teacher remarked: 'It was something that the children wouldn't have been exposed to in their daily life.'

The Danish researcher Pernille Clemmensen discovered in the interviews that film seemed to prove helpful for students to share thoughts without having to talk about themselves: 'The thing that film can do is to create a common third to speak from [an activity belonging to both practitioners and young people, providing a shared external focus]. And that opens up much easier conversations about difficult topics because it comes from a different starting point and isn't directly about the students.' The writer Michael Husen (2012: 48) defines the same concept within a social-pedagogical context: 'The most constructive form of experience takes place when the child and the adult (or the children and the adults), jointly complete a work process around a shared goal, that does not touch on their mutual relationships.'

Clemmensen recounts how, within the project, the task of discovering a film became an activity that the students and their teachers shared. The character of Paddington, for example, works well in this context - it could be argued that much of the power of his character arises from the fact he is a bear, rather than a human being. This removes the focus on ethnicity and makes it possible for students to talk about the themes of the film together in a manner that is less contentious.

The researcher Michelle Cannon found in her interviews that film sparked 'great conversations' about history, cultural processes and social identity for all age ranges, 
bringing up questions about war, flight and migration. Cannon found that the films were a source for sharing thoughts and impressions, as classes began discussions about fleeing one's native country and following one's own dreams, alongside conversations about homosexuality, loss, integration, forced marriages and family relations.

Teachers found that the films seemed to contribute to an increased sense of tolerance ('the world belongs to everybody') and affected some of the children's established attitudes about topics such as race and discrimination ('children don't see colour ... they're accepting of each other, they don't see race as we do'). Students were able to speak freely about subjects often categorized as sad and embarrassing, for example when they talked about the home for children in My Life as a Courgette ('It is just incredibly sad to lose your parents').

It was also found that film fostered reflections on children's home countries. In many instances, children shared with each other where they came from, and showed empathy with a character that represented the perspective of migrants and their problems when entering a new world. One teacher remarked:

Many of the children had a great deal of sympathy for Paddington. And they could easily identify with the many problems he encountered by being in a new place. I felt they had a lot of empathy for his situation and couldn't understand why people weren't more welcoming towards him.

In general, the results of post-screening activities showed how children connected the films to their real world: for example, they developed opinions about how they might help an immigrant such as Paddington in real life (see Figure 5 and Figure 6).

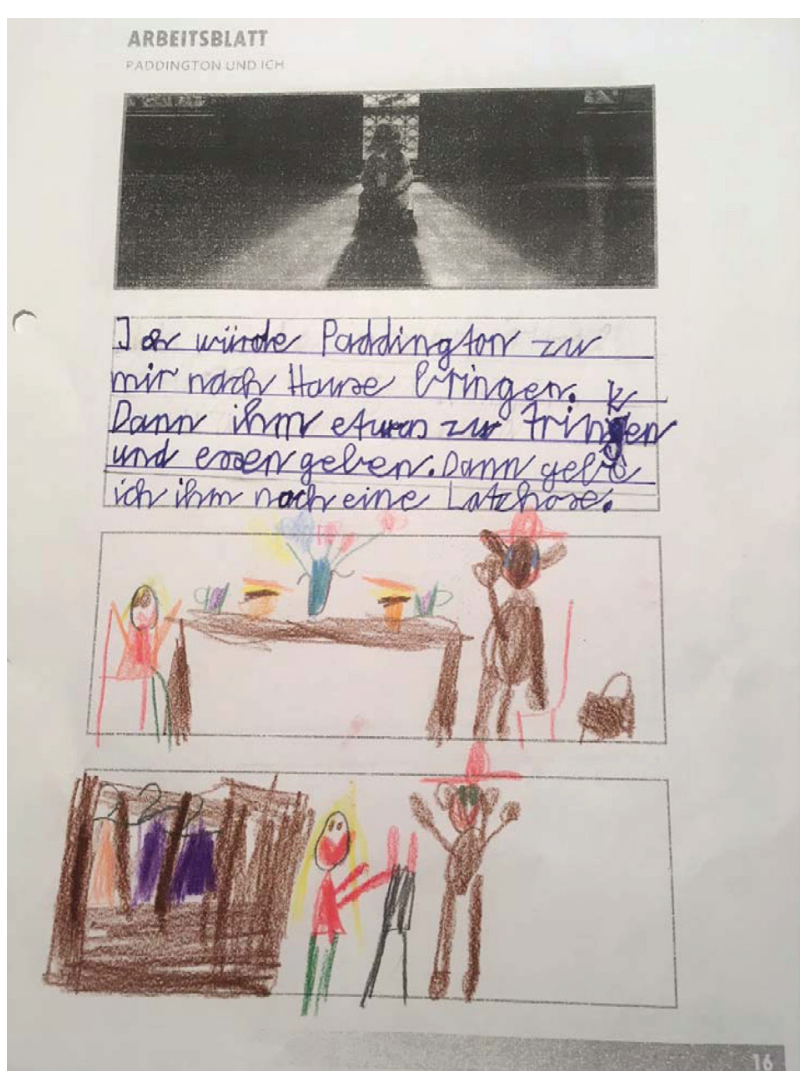

Figure 5: A primary school student from the south of Germany wrote: 'I would bring Paddington to my home. Then I give him something to drink and eat. Then I give him flap trousers.' 


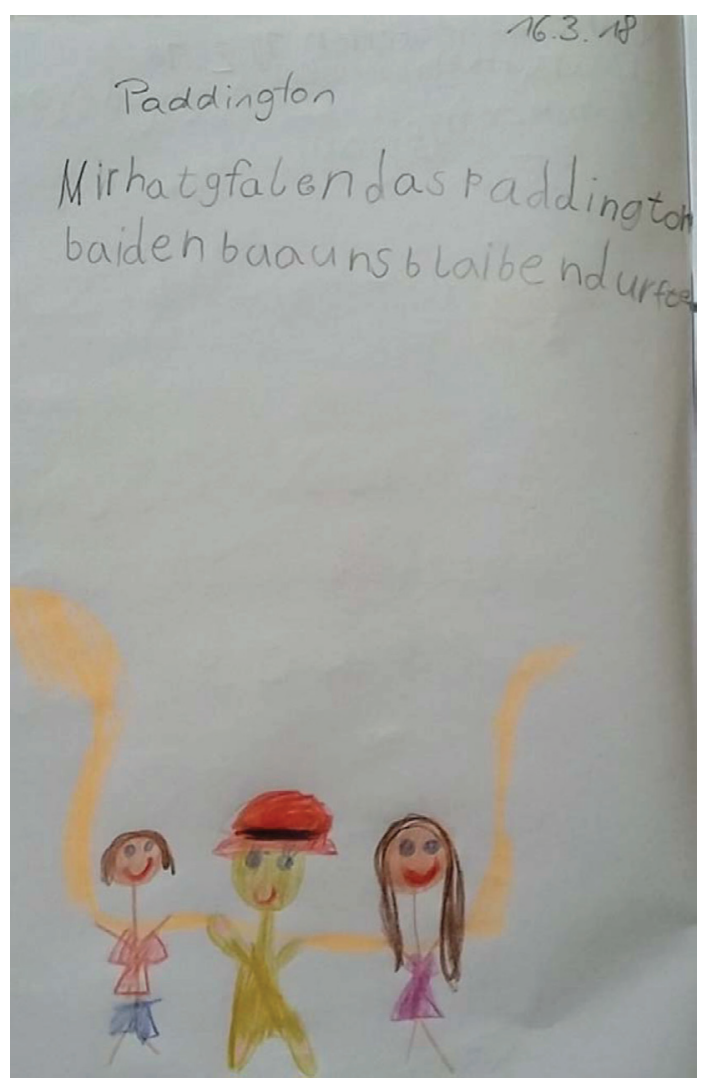

Figure 6: Primary school child's commentary on the film Paddington: 'I liked it that Paddington was allowed to stay with the Browns.'

In addition, teachers found that children were able to compare the immigrant background of a character such as Paddington with their own, and could very much understand the fears of arriving in a new country (in one instance, a boy from Syria who spoke little German was able and willing to share his background). Students learned how film is able to express particular perspectives through certain angles and 'point of view' shots, and were thus able to think about perceptions of self and other, stereotypes and prejudices. For example, secondary school students who seemed to have fixed opinions about the question of what is special about being a boy or a girl reflected on their thoughts after they explored the character of Billy Elliot, as a teacher describes:

And after the whole thing, the students took up the subject again by themselves and said: 'That's not true at all, what we wrote down there, because Billy could dance really well and he is a boy' ... and a few hours later four guys from my class came and wanted to join my dance club.

Within the project, students shared their own statements and interpretations of the films, both as works of art and within the context of society. For the teachers, these dialogical literacy events centred around film screenings brought to light powerful observations about how children view others and the ways in which they think others should be treated. One teacher remarked: 'The film[s] made me think how children accept newcomers far more easily than adults.' Many teachers within the project reflected that the perception of difference is not necessarily innate, and that it seemed 
rather a learned behaviour emerging from processes of socialization within particular environments.

\section{Challenges and obstacles}

Teachers across the project found that the visits to the cinema and the activities surrounding the screenings of the films captivated the children. On the one hand, children felt for the characters depicted in the films and enjoyed their experiences with them. On the other hand, the selection of films posed certain challenges. Some teachers reported that, just as a visit to the cinema was a very personal experience for the class, it was also a personal challenge for them as teachers. However, most found that the emotional maturity of the students was a huge factor, because for many of the reflection tasks accompanying the films, the ability to change perspective was a prerequisite.

For some of the youngest participants in the project, the screenings provided their first experience of going to the cinema. Teachers described how primary school children displayed a range of emotions while watching films (see Figure 7 and Figure 8). They cuddled up with each other and even with the teacher when scenes caused anxiety. Tears of joy and relief were visible from both boys and girls, and at other moments a sense of uncertainty was expressed.

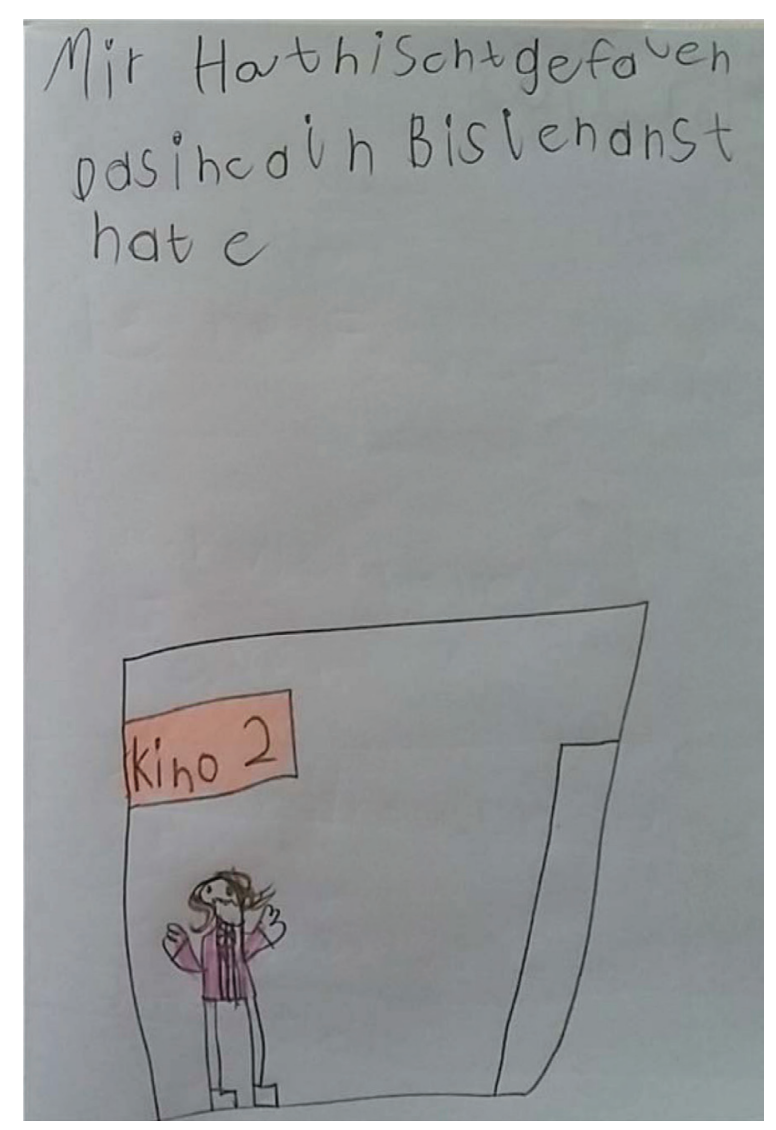

Figure 7: Primary school child's commentary on the cinema visit: 'Cinema 2, I didn't like it that I was scared a little bit.' 


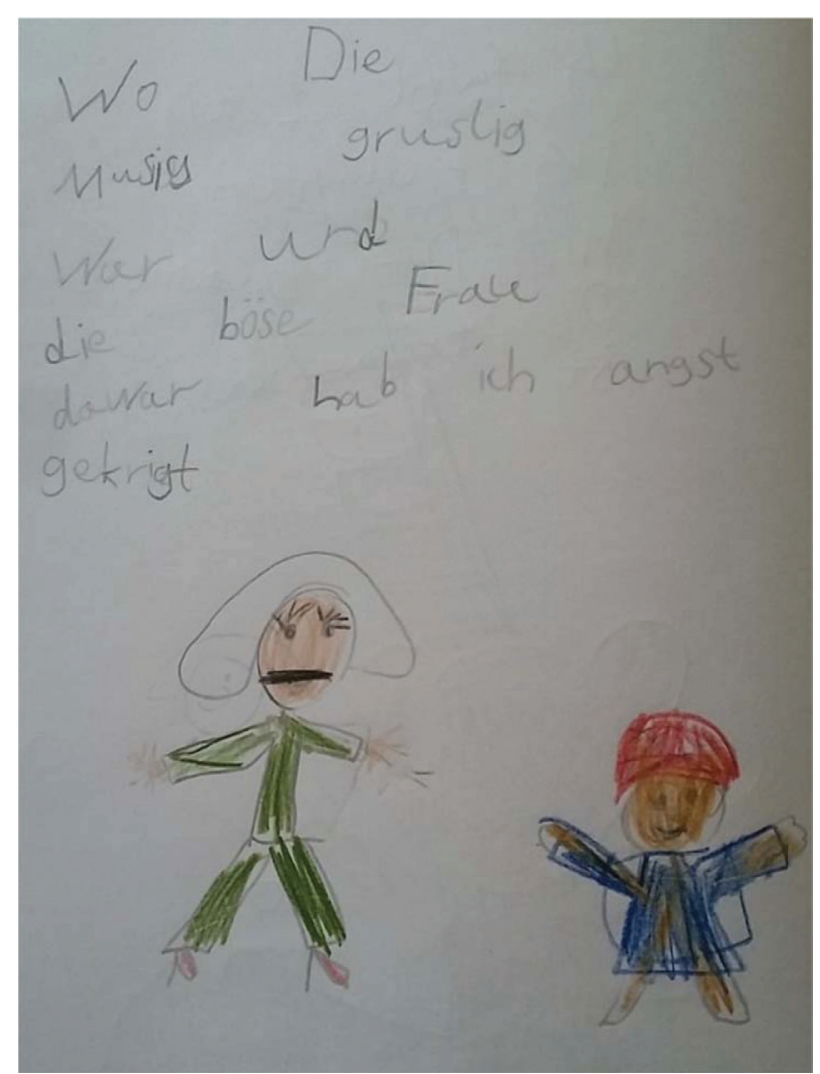

Figure 8: Primary school child's commentary on the Paddington screening: 'When the music was spooky and the mean woman showed up, I got scared.'

Teachers noticed challenges relating to film content: many secondary school students stated that they did not understand the issue and historical context of 'strike-breakers' in the British miners' strikes of the 1980s in Billy Elliot. Students, and also teachers, were not prepared for the issue of sexuality in My Life as a Courgette and in Billy Elliot. Especially from fifth-grade students, there were rejections of some scenes with sexual content during the screenings. One teacher remarked: 'The boys and girls in the cinema got really excited and asked: "Is the film really suitable for our age?" And they found that a bit disgusting.'

Teachers in the UK noted challenging, 'tricky' themes within the selected films that might provoke 'hard conversations' for which teachers may not be adequately prepared. As history was often presented in a partial and perhaps biased way within the films, teachers sometimes found themselves feeling challenged. Nevertheless, a teacher mentioned that 'We should be talking about it more collectively and not be afraid to do some unpicking.'

Looking back at the different dimensions of knowledge described by Charlton (2004) - procedural knowledge (such as drawing conclusions), declarative knowledge (such as knowing the properties of things) and media-related knowledge (such as a knowledge of genre categories) - it would seem that students participating in the Film: A Language Without Borders project stood to acquire a considerable degree of procedural knowledge: for example, in sessions where they were able to compare situations from the films with their own actions and those of others within society. A next step here would be to bring more declarative and media-related knowledge into the process, which was expressed less within the project, given the specific focus of the teaching materials on inclusive processes. I argue, therefore, that a deeper 
understanding of film history and film language itself might be considered as an additional, complementary focus for similar project work within European film education in the future. The Film: A Language Without Borders project demonstrates, however, that film literacy is not always a goal itself, but can be productively connected to the emotions and experiences that students are able to discuss after the screenings. In this way, students might be able to deepen their learning further about how film works as a medium and why film-makers choose to picture a character such as Paddington or a conflict such as that depicted in Billy Elliot in a specific way.

\section{Conclusion: Getting a bigger picture?}

The project Film: A Language Without Borders, with its selection of high-quality European films, seems to have afforded children and young people in Germany, Denmark and the UK a variety of approaches to film reception and to how one might respond creatively to the experience of cinema.

Looking through the lenses of Spinner's aspects of literary learning (2006), this study makes clear that such a project helps children and young adults in developing their skills in 'understanding the perspectives of characters in literature' (here: film) and 'becoming familiar with literary discussion' (here: discussions surrounding film). It would seem that not only the students, but also the teachers, seemed to enjoy talking about film, and teachers felt that they needed to become more familiar with more intense discussions of responses to various films.

Furthermore, returning to Spinner's (ibid.) aspects, through the study guides and the post-screening discussions, the children and young adults were able to develop their 'understanding of narrative and dramaturgical logic of action' as important aspects of literary learning. According to the participating teachers, all the children involved in the project were able to understand core aspects of the plots of each of the films, although certain subjects remained challenging, such as the strike in Billy Elliot. Through their drawings and discussions, students documented subjective involvement, which could be brought in line with accurate perception of film aesthetic (film language).

A short-term project cannot expect to change either students or teachers immediately. However, judging from the accounts of the participating teachers, Film: A Language Without Borders was able to facilitate a productive initial process of transcultural learning through perception and expression. Students learned to perceive their own environment and the environment of others, to gain experience, and to develop a greater awareness of their own perceptions and a greater sensitivity in taking account of the perspectives of others. The project made various forms of transcultural learning visible. Children compared their own family situation with the films, they compared their own opinions with those of classmates, and they brought other cultures from the present day, the past or from fictional film into connection with their own habits and rituals. In this respect, the project can be seen as a contribution to progressive attempts to undermine the silencing and othering (Rösch, 2013) of people in need.

This study proposes that the open-ended, often non-verbal, cues that film offers can act as a springboard to support more critical conversations and to build robust cultural repertoires. However, even if film is able to travel easily and attracts audiences, tells stories and stimulates co-creation and dialogue as a medium, it still requires the support of engaged and open-minded teachers to encourage students to engage 
with more challenging films, and to contextualize them within discussions of the perceptions, emotions and opinions to which they gave rise.

Finally, I hope this study may help us consider again the role of discussion within contemporary classrooms, for moments where children are encouraged to talk seem to be becoming a luxury that is gradually being eroded. As one teacher remarked: 'It always seems as though everything is crammed in; you don't have that time for discussion.' The social and cultural practices surrounding a film screening, as manifest in a project such as Film: A Language Without Borders, can help to foster both a collective sense of well-being and an arena for dissent, and mobilizing such practices can help to create a valuable sense of community in modern diverse classrooms. Ultimately, it would seem that film serves as an excellent point of departure for discussions that would not otherwise easily begin in the classroom, and moreover such an approach would seem to encourage students to continue their explorations, both inside and outside the classroom. As one teacher remarked: 'By putting these resources in front of children, you get more questions than you can answer.'

\section{Acknowledgements}

The research on the project Film: A Language Without Borders was made possible by the British Film Institute, the Danish Film Institute and Vision Kino. I thank the German research team, Ines Freitag-Amtmann, Johanna Rehak and Sarah-Miriam Tiedeke, for working on the interview guidelines and for collecting the data; Pernille Clemmensen for the research in Denmark; and Michelle Cannon for the research conducted in the UK. I would also like to thank the teachers and students who spent their time, and contributed their thoughts and work, to make the project successful and sustainable, and Laura Zimmermann for the new approach in the study guides.

\section{Notes on the contributor}

Petra Anders studied German literature, history and philosophy at the University of Göttingen, Germany. She received her doctorate for a study on poetry slam, became junior professor for media didactics at the University of Leipzig, and from 2016 to 2018 was Professor of German Didactics at the Free University of Berlin. Since 2018, she has been Professor of German Didactics for Primary Schools at Humboldt University of Berlin. Her research focuses on film didactics and new media literacies.

\section{Filmography}

Billy Elliot (GB 2000, Stephen Daldry)

Drømmen (We Shall Overcome, DK 2006, Niels Arden Oplev)

Emil und die Detektive (Emil and the Detectives, DE 1931, Gerhard Lamprecht)

Emil and the Detectives (USA 1964, Peter Tewksbury)

Ernest \& Célestine (BE/FR/LU 2012, Stéphane Aubier, Vincent Patar and Benjamin Renner)

Fighter (DK 2007, Natasha Arthy)

Jemima and Johnny (ZA/GB 1966, Lionel Ngakane)

Ma vie de Courgette (My Life as a Courgette, CH/FR 2016, Claude Barras)

Paddington (GB/FR 2014, Paul King)

Palle Alone in the World (DK 1949, Astrid Henning-Jensen)

The Red Balloon (FR 1956, Albert Lamorisse)

Sing Street (IE/US/GB 2016, John Carney) 


\section{References}

Albrecht, C. and Hornberger, J. (2014) 'Empirische Zugänge zu ästhetischer Erfahrung'. In Jahraus, O., Liebau, E., Pöppel, E. and Wagner, E. (eds) Gestalten und Erkennen: Ästhetische Bildung und Kompetenz. Münster: Waxmann, 49-61.

Anders, P. (2016) 'Medien als Perspektive für Inklusion? Überlegungen zum gemeinsamen Unterricht im Fach Deutsch'. In Musenberg, O. and Riegert, J. (eds) Didaktik und Differenz. Bad Heilbrunn: Verlag Julius Klinkhardt, 122-33.

Anders, P. (2018) 'Visuelle und digitale Medien'. In Boelmann, J.M. (ed.) Empirische Forschung in der Deutschdidaktik: Band 3: Forschungsfelder der Deutschdidaktik. Baltmannsweiler: Schneider Verlag Hohengehren GmbH, 231-49. Online. https://tinyurl.com/y4opucsu (accessed 1 August 2019).

Barthelmes, J. (2006) 'Erleben - Lernen - Erfahren: Der Stellenwert des Kinderkinos für die Bildungsprozesse der Heranwachsenden'. Kinder- und Jugendfilm Korrespondenz, 107, 3-11.

BFI (British Film Institute) (2019) 'Film: A language without borders'. Online. https://tinyurl.com/y3d2png7 (accessed 1 August 2019).

Charlton, M. (2004) 'Entwicklungspsychologische Grundlagen'. In Mangold, R., Vorderer, P. and Bente, G. (eds) Lehrbuch der Medienpsychologie. Göttingen: Hogrefe, 129-50.

Husen, M. (2012) Socialpædagogik og Arbejdsprocesser. Copenhagen: Socialpædagogernes Faglige Organisation.

Kepser, M. and Abraham, U. (2016) Literaturdidaktik Deutsch: Eine Einführung. 4th ed. Berlin: Erich Schmidt Verlag.

Riegert, J. and Anders, P. (2018) 'Literarisches Lernen im inklusiven Deutschunterricht: Vielfältige Textzugänge und Kommunikationswege eröffnen'. Deutsch 5-10, 55, 28-31.

Rösch, H. (2013) 'Interkulturelle Literaturdidaktik im Spannungsfeld von Differenz und Dominanz, Diversität und Hybridität'. In Josting, P. and Roeder, C. (eds) "Das ist bestimmt was Kulturelles": Eigenes und Fremdes am Beispiel von Kinder- und Jugendmedien. München: Kopaed, 21-32.

Spinner, K.H. (1998) 'Thesen zur ästhetischen Bildung im Literaturunterricht heute'. Der Deutschunterricht, 50, 46-54.

Spinner, K.H. (2006) 'Literarisches Lernen'. Praxis Deutsch, 200, 6-16.

Spinner, K.H. (2017) 'Literarisches Lernen in Verbindung mit literarischen Kompetenzen'. In Baurmann, J., Kammler, C. and Müller, A. (eds) Handbuch Deutschunterricht: Theorie und Praxis des Lehrens und Lernens. Seelze: Klett/Kallmeyer, 143-6.

Tatsch, I. (2010) 'Filmwahrnehmung und Filmerleben von Kindern'. In Josting, P. and Maiwald, K. (eds) Verfilmte Kinderliteratur: Gattungen, Produktion, Distribution, Rezeption und Modelle für den Deutschunterricht. München: Kopaed, 143-53.

Vision Kino (2018) 'Unterrichtsmaterial'. Online. www.visionkino.de/unterrichtsmaterial (accessed 31 August 2019).

Welsch, W. (1999) 'Transculturality: The puzzling form of cultures today'. In Featherstone, M. and Lash, S. (eds) Spaces of Culture: City, nation, world. London: SAGE Publications, 194-213. 